\title{
Problems and Countermeasures in the Tertiary Industry of Henan Free Trade Zone
}

\author{
Shugang $\mathrm{Ma}^{1}$, Fang Zheng ${ }^{2}$ \\ ${ }^{1}$ Hebei University of Economics and Business, Shijiazhuang, China \\ ${ }^{2}$ Hebei University of Economics and Business, Shijiazhuang, China \\ 17192981@qq.com,978914768@qq.com
}

Keywords: Henan Free Trade Zone, tertiary industry, financial system, information platform, personnel training system.

Abstract: As the successful operation of Shanghai, Guangdong, Tianjin, and Fujian Free Trade Zone, Henan, as the important province rising in central China, should seize the opportunity to achieve further development. The establishment of Henan free trade zone is very important to Henan, especially to the development of tertiary industry. The paper, by making an in-depth analysis on the current situation and main problems of the tertiary industry of Henan free trade zone, puts forth some concrete countermeasures and suggestions from the aspects of improving the level of comprehensive government services, improving the financial system and the investment environment, establishing an information-based platform, improving the personnel training system and so on.

\section{Overview of Henan Free Trade Zone and Its Tertiary Industry}

The establishment of the coastal free trade area and the initial results have found a new way for the economic growth of inland areas. In August 2016, Henan became the third batch of pilot free trade zones in China after many preparations and efforts. Since the establishment of the free trade zone, Henan has played an active role in guiding the policy, and formulated a series of development plans for its future development by combining its historical origins, regional characteristics and realistic demands. As Henan located at a number of transport arteries, it combines its geographical position advantages, and through further developing the advantages of transportation hubs. It actively constructs logistics network to promote the further development of Henan economy. At the same time, Henan responded to the call of national policy, increased investment in the tertiary industry and introduced foreign investment. The government has moved some centres of stateowned enterprises, foreign companies and large financial institutions into the free trade zone. The move of financial institutions and some large enterprises has led to the development of transportation, culture and other industries within the free trade zone. This positive external effect on the development of Henan free trade zone's tertiary industry has played a driving role. Due to historical factors, economic factors and other reasons, the development of tertiary industry in Henan is relatively backward compared with the development level of primary and secondary industries, and the tertiary industry has not become the main force driving economic growth.

Gengxiang $\mathrm{Li}$ considered the establishment of Henan free trade zone from various 
aspects(Gengxiang Li,2015); Zheng Wan also takes Shanghai free trade zone as an example to analyse the benefits brought by the establishment of free trade zone under the new policy background, which has reference significance for the development of Henan free trade zone(Zhang Wan, 2014). Shaole Zhang analysed the new form of Henan free trade zone by connecting "One Belt And One Road" with Henan free trade zone, and put forward relevant Suggestions (Shaole Zhang, 2018). Dafeng Yang comprehensively analysed and summarized the advantages, disadvantages, opportunities and challenges of Henan province through SWOT analysis of establishing free trade zone in Henan province(Dafeng Yang,2016); Fengjuan Yang studied the development status of tertiary industry in Henan free trade zone, and made an empirical analysis on the competitiveness of various industries in Henan(Fengjuan Yang,2014). Zhiyuan Yang etc,. provided a new idea for the development of Henan's service industry by introducing the development of the service industry in Shanghai and the open research on the Shanghai free trade zone(Zhiyuan Yang,2013). Yi-chi established a comprehensive analysis framework by introducing the influence of ports on the free trade zone, which is of certain reference significance for Henan province to play the role of Zhengzhou airport (Yi-chi,2009). Lisa Guo analysed the new problems faced by Henan province in the new era and put forward effective suggestions (Lisa Guo,2018). Hexiang Xue proposed his own suggestions for the next strategic positioning of Henan province by using the comparative analysis research method (Hexiang Xue, 2016). Wei Chen etc, took Shanghai free trade zone as an example to study the development of logistics industry and supply chain within the free trade zone (Wei Chen, 2014). Li Xiong took Fujian as the research object and analysed a series of problems, which are of great reference value for the further development of Henan free trade zone (Li Xiong, 2018). On this basis, this paper starts from the macro background of the establishment of Henan free trade zone, analysed the influence of the policy and the existing problems of Henan free trade zone in developing the tertiary industry, and puts forward relevant suggestions.

\section{The Main Problems in the Tertiary Industry}

The establishment of Henan free trade zone has brought opportunities for the development of the tertiary industry in Henan, but many problems have arisen during the development process, especially for the development of the tertiary industry. The main problems are as follows:

\subsection{The Lack of Comprehensive Service Capacity of the Government Affects the Improvement of Efficiency}

The construction of comprehensive service government plays an important role in improving economic efficiency. The construction of Henan free trade zone puts forward higher requirements to the government's comprehensive service level and capacity. At present, the government has a single means of punishment, mainly including fines. The informatization level of the government, the network service platform, and the construction of the client are deficient, which reduces the efficiency. The repetitive working process and complicated procedures reduce the enthusiasm of staff in the free trade zone. Meanwhile, the government's accountability mechanism and assessment mechanism are not transparent and lack effective supervision from all walks of life.

\subsection{The Financial Industry Cannot Provide Complete Financial Services to The Market and Reduce the Development Efficiency of the Tertiary Industry}

The establishment of Henan free trade zone provides opportunities for the development of Henan's financial industry, but it also generates many problems. On the one hand, the financial 
service system is not perfect. Banks, securities, guarantees, funds, insurance companies and other financial institutions cannot provide diversified and multi-functional supporting services. On the other hand, the risk prevention and control system and financial innovation are inadequate. The financial industry is an industry with great risks. If the risk is not well controlled, economic fluctuations will occur and systematic financial risks will be triggered. In this way, the security of the whole market will be endangered and the development of the economy and enterprises will be adversely affected. Henan financial market lacks perfect financial supervision and regulation institutions and financial data statistical mechanism in risk prevention and control, and cannot make effective analysis on financial data and respond to market changes as soon as possible. At the same time, the introduction of more advanced, better risk prevention goods don't make true. The prevention and control of financial risks is not well done, and the financial system and the innovation of financial products are not well done, too.

\subsection{The Low Proportion and Low Level of the Service Industry Will Affect the Improvement of the Economic Level}

The development of the service industry can promote the upgrading of the industrial structure, and then drive the improvement of the economy. On the one hand, the development of service industry in Henan province has low contribution to the province, and the proportion of service industry is not high. The service sector accounted for 42.7 percent in Henan province in 2017, lower than the national average of 51.6 percent, and there is a large gap compared with other provinces. The low proportion of the service industry reduces the beneficial impact of the service industry on the upgrading of the industrial structure. At the same time, the cultural service industry in Henan province needs to be further promoted. Although the impact of medical treatment, culture, entertainment, tourism and other industries on economy has been improved in Henan province, the number of industries is relatively small, and the scale economy has not been formed. Therefore, the driving effect on economy is not obvious, and it has not become the main force driving the service industry production in Henan province. In the development of Henan's cultural industry, there is a large gap between the level of cultural manufacturing and the level of cultural services. The cultural manufacturing industry accounts for a large proportion, and human capital plays a role in the cultural manufacturing industry. Compared with this, the process of transforming cultural creation and cultural innovation into new productive forces is slow, which cannot be the driving force for further economic development.

On the other hand, the industrial layout of the service industry in Henan province is unbalanced. Data show that after the establishment of the free trade zone, the proportion of the service industry in different regions is inconsistent. Among them, Zhengzhou, with the highest proportion, is 51.7\%, followed by Luoyang, with $47.8 \%$, and Kaifeng with a ratio of $44.5 \%$, while other cities have a very low proportion. Therefore, the imbalance of different local service industries in Henan province restricts the coordinated development of Henan's service industry.

\subsection{Lack of High-End Talents Makes the Development of the Tertiary Industry Lack Vitality}

In the development of modern economy, human capital is a particularly important factor. The construction of Henan free trade zone is inseparable from the input of human capital. In the development and construction of Henan free trade zone, there is a lack of complete talent introduction system. The lack of high-end talents is not conducive to the further development of Henan free trade zone. At the same time, there is a lack of a complete and systematic talent cultivation system. The regional difference of education investment and the difference of basic and technical education make it difficult to adapt to the market demand for talents. Data show that in the 
academician of Chinese academy of sciences of Henan have 19 people, accounting for $1.25 \%$ of the total number of academician of Chinese academy of sciences. Henan has 2492 people enjoy the state council special allowance of high-level experts, accounting for $1.45 \%$ of the total. The number of high-end talent in Henan province is very little, so the introduction of high-end complex talents is an important problem in the development of Henan continue developing.

\subsection{Imperfect information platform construction reduces the efficiency of cooperation between different departments}

In the network age, the cost of information acquisition and exchange is very low, but it is not easy to break the barrier of connection between different information. Without breaking down the barriers of accessing and exchanging of information, the cost of cooperation between each other will be very large, especially under the premise of higher requirements for efficiency and cost nowadays. Henan free trade zone lacks the information system among different departments, and the barriers of information exchange and information sharing among different parts are relatively large. For the tertiary industry, insufficient information exchange and sharing will hinder its further development. For example, lack of enterprises' registration and filing management within the free trade zone, registration management, risk management information system of financial enterprises, and supervision system for all enterprises. Lack of information sharing platform between daily management department, supervision department, financial department, transportation department and other departments; At the same time, it is impossible to supervise the dynamic development of enterprises and avoid the risk of illegal operation from the source. The imperfect information platform construction has affected the further development of the tertiary industry.

\section{Some Suggestions of the Tertiary Industry}

\subsection{Improve the Government's Ability to Provide Comprehensive Services and Accelerate Economic Development}

The further development of Henan free trade zone requires the government to further enhance service awareness and improve the level of comprehensive services. First, change work consciousness, update development idea, innovate work way. All departments of the government serve the development of the free trade zone and carry out various services on this basis. Second, speed up the improvement of government informatization level. In the network era, the government should keep up with the pace of the era, and establish the network platform and client. Many businesses can be handled directly from the Internet, which not only improves the efficiency, but also makes enterprises run less. The government also needs to re-examine the work procedures and procedures, merge and duplicate, discard the useless, and further improve the government's work efficiency and comprehensive service level. Finally, the establishment of supervision mechanism should be strengthened. The government should take its duty of supervision over the market, supervise the daily operation of the market. It's also the government's duty to disclose related matters stipulated by relevant national laws and regulations, to accept the supervision voluntarily, and to create a good environment for the development of the free trade zone.

\subsection{Accelerate Reform of the Investment and Financing Systems}

To promote economic development, it's important to balance the relationship between government and market. In the market economy, the government exerts the guidance, the standardization function, and takes the enterprise as the main body participates in the market 
economy activity. As the market subject, enterprises should follow the government's system in terms of investment and financing, strictly implement the negative list system, and control the risk of investment. At the institutional level, the government should create an open and transparent investment and financing environment to stimulate the innovation capacity of enterprises. At the same time, the government should improve investment system. In principle, the government can only make non-profit investment within the free trade zone, and inject new vitality into the market mainly through direct investment. In order to strengthen the supervision of the government, a multisectoral joint regulator can be established to make the market more fair and efficient. It's necessary to expand financing channels, and vigorously develop direct financing to reduce the difficulty of financing for small and medium-sized enterprises. The government encourage enterprises in the region to go public for financing. The government should set up sound investment funds, and use market-oriented methods of operation to promote the development of characteristic industries and emerging industries in the region. All the measures can accelerate the reform of financial system, promote the development of tertiary industry, and inject vitality to the development of Henan free trade zone.

\subsection{To Guide Foreign Investment and Promote Coordinated Economic Development}

The government should actively introduce foreign capital, use it to drive the development of enterprises in free trade zones. All enterprises should strictly observe the conditions for granting access to foreign businesses in advanced manufacturing and modern service industries in accordance with relevant state policies and regulations. First, foreign investors can be encouraged to invest in agriculture in Henan province. Henan province is a big agricultural country. Agricultural development, food production are related to the economic development of this province. At the same time, the agricultural also affects the stability and security of the whole country's food supply. Through the introduction of foreign capital, the investment in agriculture, including the development of agricultural mechanization, the development of new pesticides, the latest cultivation technology, and cultivate new varieties, the development of green agriculture, high-tech agriculture, agricultural mechanization, cannot leave the capital support. Foreign capital enters this field also have a food security concerns, but due to at the preliminary stage of agricultural development in Henan province, so the foreign capital can allow to enter.

Second, encourage foreign investment in advanced manufacturing. Guide foreign investment in intelligent manufacturing, green manufacturing and other advanced manufacturing industries. Advanced manufacturing industry is the pillar industry in Henan province. The investment of foreign capital can provide an opportunity for industrial upgrading in Henan province. Finally, to provide good basic services for the further development of Henan economy, foreign investment in infrastructure construction in Henan is encouraged.

\subsection{Accelerate Financial System Innovation and Prevent Financial Risks}

The successful operation of the Shanghai free trade zone, especially the innovation in the financial field, has provided replicable successful experience for the development of Henan free trade zone. On the basis of drawing lessons from Shanghai and other free trade zones, Henan can combine its own advantages and development needs to carry out further financial system innovation. First, financial products can be innovated. Develop different portfolio financial products to meet the market demand for diversified products and provide customers with a variety of choices to avoid risks. Develop products that meet customer needs to meet market and new needs. Second, it need learn from the new foreign exchange management model and learn from the experience of developed countries and carry out new pilot projects in free trade zones. On the premise of ensuring 
the safety of foreign exchange, the government should give more space to enterprises and give full play to their autonomy. The innovation of financial system can provide a new choice for the development of real economy. The enterprises can combine with the development and needs of real economy, meet the demand of real economy and market participants for new financial products to better serve economic development.

\subsection{Promoting the Development of Trade in Services and Accelerating the Construction of Information Platforms}

The establishment of China (Zhengzhou) cross-border e-commerce comprehensive pilot zone is a policy advantage for Henan to develop the tertiary industry. Henan should give play to local characteristic advantage on this foundation, and the positive exterior effect of industrial agglomeration. Henan should carry out new pilot of electronic commerce, combine science and technology to achieve innovate new mode. It also can carry out the development strategy of "bringing in" and "going out", actively promote the development process of service trade, expand the cooperation with the service trade of peripheral countries of "One Belt And One Road", and learn advanced experience to continuously improve the development level of Henan free trade, and improve its international influence and competitiveness. The government speed up the construction of information platform, establish basic database of different enterprises in the free trade zone, strengthen the dynamic supervision of enterprises, and at the same time establish information sharing platform between different departments, strengthen the coordination between departments, and improve the efficiency of cooperation in the free trade zone.

\subsection{Establish A Sound Personnel Training System}

Talents, especially high-level talents, are an important factor in promoting economic development. Talent provides new ideas, new ideas and new technologies for economic development. Without talent cultivation and introduction, the development of economy will show the problem of insufficient staying power. Henan free trade zoo should establish a perfect talent cultivation system, introduce high-end and professional talents, and solve the problem of insufficient follow-up force in the development of tertiary industry. Due to historical factors, underdeveloped economy and insufficient cultural input of education, there is a lack of high-level talents in Henan. In addition to economic development level and social and cultural factors in Henan, a large number of talents are lost, and it is also difficult to introduce and retain talents. For the further development of Henan free trade zone, reform of education system and education system should be promoted, and more attention and input should be paid to cultural education. In the process of education, the combination of science and practice should be advocated, and emphasis should be placed on practical ability.

For the introduction of high-end talents, relatively loose scientific research environment and sufficient scientific research funds should be provided for professional researchers, and the level of treatment should be improved, as well as the arrangement of family members. At the same time, attention is paid to the cooperation between different scientific research projects, and different levels of rewards are given to scientific researchers to obtain research results, so as to further stimulate the enthusiasm and creativity of talents and make further efforts for talent cultivation and introduction. Through the talent factor, Henan free trade zone, and the development of the tertiary industry to provide new impetus. 


\section{Conclusions}

The establishment of Henan free trade zone provides new historical opportunities for Henan. Henan should pay more attention to cultivating new competitive advantages on the basis of giving play to the advantages of free trade zone, especially to accelerate the investment and development of tertiary industry. It will bring benefits to promote cooperation with the neighbouring countries of One Belt And One Road, expand our advantages and make up for our deficiencies. At the same time, the government should actively introduce new technologies and talents to inject new vitality into our economic development. Under the new situation, Henan free trade zone should constantly learn and learn from the development and construction of other free trade zones, and combine with the actual situation of Henan, increase the investment in the tertiary industry, and use the development of the tertiary industry to drive the further development of Henan's economy.

The development of Henan free trade zone provides a development platform for Henan, bringing new resources and opportunities to Henan. The tertiary industry is a new growth point for the further development of Henan free trade zone. Under the guidance of the development plan, the government should actively improve the system, input resources, introduce high-end talents and attract foreign capital, and give full play to the initiative of the people in the free trade zone to encourage new ideas and ideas to jointly promote the development of Henan free trade zone.

All in all, Henan free trade zone has a good chance to achieve its further development. The government should encourage the enterprises to development their own strengths. The enterprises need to seize the chance to gain more benefits and reform their structures that hinder the enterprise development. Only in this way, the enterprises can get a more bright future in the future. The corporation between the government and the enterprises is a good symbol.

The establishment of Henan free trade can bring benefits to the person in the free trade zone. This is a good chance for them to practice their own idea and the government can help them by giving them some preferential policy.

It is a good chance for Henan to development economic, especially to the tertiary industry. Henan free trade zone can make Henan achieve another further development.

\section{References}

[1] Dafeng Yang, 2016. A SWOT analysis of establishing a free trade zone in Henan province, Journal of Huang he university of science and technology. 18(01),pp.27-31.

[2] Fengjuan Yang, 2014. An empirical study on the development and competitiveness of tertiary industry in Henan province, Journal of Henan University. 54(05),pp.13-18

[3] Gengxiang Li, Xicheng Wang, 2015. Some thoughts on the construction of Henan pilot free trade zone, Henan sociology. 23(06),pp.63-70.

[4] Hexiang Xue, 2016. Functional orientation and strategic measures of China (Henan) free trade zone -- a comparative study based on domestic free trade zone, The northern economic and trade. (06),pp.4-5.

[5] Lisha Guo, 2018. Problems and countermeasures of the development of modern service industry in Henan under the background of building a strong modern service industry, Journal of CPC Zhengzhou party school. (04),PP.78-82.

[6] Shaole Zhang, 2018. The new situation of Henan free trade zone construction and countermeasures and suggestions, Journal of Huang he University of science and technology. 20(02),pp.61-71.

[7] Wan Zheng, 2014. Policy and politics behind Shanghai's Free Trade Zone Program, Journal of Transport Geography. (34),pp.34-36.

[8] Wei Chen, He Hua Li. 2014. The Impact of Shanghai Pilot Free Trade Zone on Logistics Industry, Advanced Materials Research. 3470(1030),pp.21-24.

[9] Xiong Li, Mei Zhong, 2018. Study on the Effects of Industrial Agglomeration in Polit Free Trade Zone-the Case of China Polit Free Trade Zone, IOP Conference Series: Materials Science and Engineering. 394(4),pp.35-37.

[10] Yi-Chi h Yang, 2009. A Comparative Analysis of Free Trade Zone Policies in Taiwan and Korea based on a Port Hinterland Perspective, The Asian Journal of Shipping and Logistics. 25(2), pp.21-26. 
[11] Zhiyuan Yang, Wenjun Tan, Tinghai Zhang, 2013. China pilot free trade zone study on service opening, Economic trends. (11), pp.58-67. 